\title{
Control of Variable Speed Variable Pitch Wind Turbine at Above and Below Rated Wind Speed
}

\author{
Saravanakumar Rajendran and Debashisha Jena \\ Department of Electrical Engineering, National Institute of Technology Karnataka, Surathkal 575025, India \\ Correspondence should be addressed to Debashisha Jena; bapu4002@gmail.com
}

Received 12 May 2014; Revised 1 October 2014; Accepted 3 October 2014; Published 22 October 2014

Academic Editor: Adrian Ilinca

Copyright (C) 2014 S. Rajendran and D. Jena. This is an open access article distributed under the Creative Commons Attribution License, which permits unrestricted use, distribution, and reproduction in any medium, provided the original work is properly cited.

\begin{abstract}
The paper presents a nonlinear approach to wind turbine (WT) using two-mass model. The main aim of the controller in the WT is to maximize the energy output at varying wind speed. In this work, a combination of linear and nonlinear controllers is adapted to variable speed variable pitch wind turbines (VSVPWT) system. The major operating regions of the WT are below (region 2) and above rated (region 3) wind speed. In these regions, generator torque control (region 2) and pitch control (region 3) are used. The controllers in WT are tested for below and above rated wind speed for step and vertical wind speed profile. The performances of the controllers are analyzed with nonlinear FAST (Fatigue, Aerodynamics, Structures, and Turbulence) WT dynamic simulation. In this paper, two nonlinear controllers, that is, sliding mode control (SMC) and integral sliding mode control (ISMC), have been applied for region 2, whereas for pitch control in region 3 conventional PI control is used. In ISMC, the sliding manifold makes use of an integral action to show effective qualities of control in terms of the control level reduction and sliding mode switching control minimization.
\end{abstract}

\section{Introduction}

In recent years, wind energy is one of the major renewable energy sources because of environmental, social, and economic benefits. The major classification of wind turbines (WT) is fixed speed wind turbine (FSWT) and variable speed wind turbine (VSWT). Compared with FSWT, VSWT have many advantages such as improved energy capture, reduction in transient load, and better power conditioning [1]. For any kind of WT, control strategies play a major role on WT characteristics and transient load to the network [2]. In VSWT the operating regions are classified in to two major categories, that is, below and above rated wind speed. At below rated wind speed the main objective of the controller (i.e., torque control) is to optimize the wind energy capture by avoiding the transients in the turbine components especially in the drive train. At above rated wind speed the major objective of the controller (i.e., pitch control) is to maintain the rated power of the WT. For extracting the maximum power at below rated wind speed the WT rotor speed should operate at reference rotor speed which is derived from effective wind speed. In general wind speed is measured by the anemometer which is varying along the rotor shift area so it is difficult to get the mean wind speed by this measurement. Several literatures are addressing this issue by estimating the effective wind speed. But some other literatures assume that the effective wind speed is directly available $[3,4]$. In [5] a combination of proportional integral (PI) and SMC is used to adjust the turbine rotor speed for extracting maximum power without estimating the wind speed. In [6] a PI based torque control is used to control the WT, where optimal gains are achieved by particle swarm optimization and fuzzy logic theory, without estimating the wind speed. Estimation of effective wind speed by an inversion of static aerodynamic model with known pitch angle is discussed in [7]. Nonlinear static and dynamic state feedback linearization control is addressed in $[8,9]$ where both the single- and two-mass model are taken into consideration and the wind speed is estimated by using Newton Raphson (NR). To accommodate the parameter uncertainty and robustness a higher order 


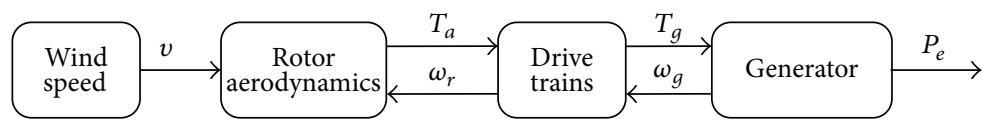

Figure 1: Schematic of WT.

sliding mode controller is proposed in [10], which ensures the stability of the controller in both the regions that is, below and above rated speed. An extended Kalman Filter based wind speed estimator is discussed in [11], which uses the conventional ATF and ISC for controlling the WT. In [12] fuzzy logic control has been proposed and the effective wind speed is estimated using sequential Monte Carlo simulator. Discrete time optimal LQR/LTR based on optimal quadratic function is studied in [13]. In [14] the effective wind speed is estimated by the frequency domain data fusion and the observer is formulated based on the mixed sensitivity problem with linear matrix Inequalities.

For above rated wind speed authors in [15] discussed the multivariable control strategy by combining the nonlinear state feedback control for region 2 with linear control for region 3 . Finally the results are compared with the existing control strategy such as PID and LQG. In [16] the WT controller is the combination of linear control for blade pitch angle with $H_{\infty}$ nonlinear torque control. Nowadays fuzzy and neural networks (NN) are the powerful soft computing methods for controlling nonlinear systems. Authors in [17] discussed a fuzzy $P+I$ and neurofuzzy controller for controlling the WT at above rated wind speed. PSO is used to train the adaptive neurofuzzy controller. WT control using adaptive radial basic $\mathrm{NN}$ used for both pitch and torque controller is addressed in [18]. Active disturbance rejection based pitch control for variable speed WT is presented in [19], where the extended state observer is used to estimate the state variable and disturbance. In [20] the controller has two parts, that is, nonlinear feed-forward path and linear feedback path. The feed-forward path uses the information about the desired power output, wind velocity, and the turbine speed to determine the pitch angle required. In [21] NN based pitch angle control is implemented by using multilayer perceptrons with back propagation learning algorithm and radial basis function network for tuning the pitch controller.

This paper uses a PI control for pitch control and two nonlinear controllers such as SMC and ISMC for torque control. The paper is organized as follows. Section 2 discusses the modeling of two-mass model. Problem formulation and control objectives are discussed in Section 3. The proposed controllers for all the regions are discussed in Section 4. Section 5 discusses the validation of the results using FAST simulator. Finally in Section 6 a conclusion is drawn from the obtained results, which concludes that the proposed controllers are working fine for controlling the WT at below and above rated wind speed.

\section{WT Model}

WT is a device which converts the kinetic energy of the wind in to electric energy. Simulation complexity of the WT purely depends on the type of control objectives. In case of WT modelling complex simulators are required to verify the dynamic response of multiple components and aerodynamic loading. Generally dynamic loads and interaction of large components are verified by the aeroelastic simulator. For designing a WT controller, instead of going with complex simulator, the design objective can be achieved by using simplified mathematical model. In this work WT model is described by the set of nonlinear ordinary differential equation with limited degree of freedom. This paper describes the control law for a simplified mathematical model with the objective of optimal power capture at below and above rated wind speed. The proposed controllers are validated for FAST WT model in three different cases of wind speed profile such as below rated wind speed (region 2), above rated wind speed (region 3) and a smooth transition between these two wind speeds (region 2.5). The parameter of the two-mass model is given in Appendix A. Generally VSWT system consists of the following components, that is, aerodynamics, drive trains, and generator, shown in Figure 1.

Equation (1) gives the nonlinear expression for aerodynamic power capture by the rotor

$$
P_{a}=\frac{1}{2} \rho \pi R^{2} C_{P}(\lambda, \beta) v^{3}
$$

From (1) it is clear that the aerodynamic power $\left(P_{a}\right)$ is directly proportional to the cube of the wind speed. The power coefficient $C_{P}$ is the function of blade pitch angle $(\beta)$ and tip speed ratio $(\lambda)$. The tip speed ratio is defined as ratio between linear tip speed and wind speed:

$$
\lambda=\frac{\omega_{r} R}{v} .
$$

Generally wind speed is stochastic nature with respect to time. Because of this, tip speed ratio gets affected, which leads to variation in power coefficient. The relationship between aerodynamic torque $\left(T_{a}\right)$ and the aerodynamic power is given in (3)

$$
\begin{gathered}
P_{a}=T_{a} \omega_{r}, \\
T_{a}=\frac{1}{2} \rho \pi R^{3} C_{q}(\lambda, \beta) v^{2},
\end{gathered}
$$

where $C_{q}$ is the torque coefficient given as

$$
C_{q}(\lambda, \beta)=\frac{C_{P}(\lambda, \beta)}{\lambda} .
$$

Substituting (5) in (4) we get

$$
T_{a}=\frac{1}{2} \rho \pi R^{3} \frac{C_{P}(\lambda, \beta)}{\lambda} v^{2} .
$$


TABLE 1: Coefficients values.

\begin{tabular}{lc}
\hline$a_{0}=0.1667$ & $a_{3}=-0.01617$ \\
$a_{1}=-0.2558$ & $a_{4}=0.00095$ \\
$a_{2}=0.115$ & $a_{5}=-2.05 \times 10^{-5}$ \\
\hline
\end{tabular}

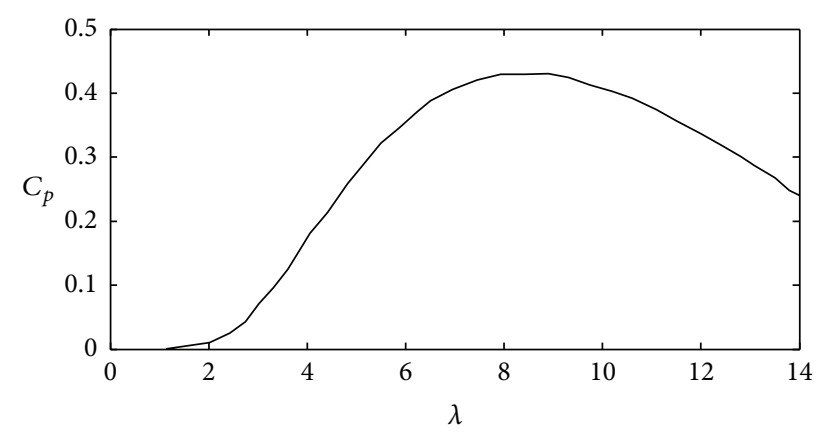

Figure 2: $C_{p}$ versus $\lambda$ curve.

In above equation the nonlinear term is $C_{p}$ which can be approximated by the 5 th order polynomial given in (7)

$$
C_{P}(\lambda)=\sum_{n=0}^{5} a_{n} \lambda^{n}=a_{0}+\lambda a_{1}+\lambda^{2} a_{2}+\lambda^{3} a_{3}+\lambda^{4} a_{4}+\lambda^{5} a_{5},
$$

where $a_{0}$ to $a_{5}$ are the WT power coefficient.

The values of approximated coefficients are given in Table 1. Figure 2 shows the $C_{p}$ versus $\lambda$ curve.

Figure 3 shows the two-mass model of the WT. Equation (8) represents dynamics of the rotor speed $\omega_{r}$ with rotor inertia $J_{r}$ driven by the aerodynamic torque $\left(T_{a}\right)$ :

$$
J_{r} \dot{\omega}_{r}=T_{a}-T_{\mathrm{ls}}-K_{r} \omega_{r} .
$$

Breaking torque acting on the rotor is low speed shaft torque $\left(T_{\mathrm{ls}}\right)$ which can be derived by using stiffness and damping factor of the low speed shaft given in (9):

$$
T_{\mathrm{ls}}=B_{\mathrm{ls}}\left(\theta_{r}-\theta_{\mathrm{ls}}\right)+K_{\mathrm{ls}}\left(\omega_{r}-\omega_{\mathrm{ls}}\right) .
$$

Equation (10) represents dynamics of the generator speed $\omega_{g}$ with generator inertia $J_{g}$ driven by the high speed shaft torque $\left(T_{\mathrm{hs}}\right)$ and braking electromagnetic torque $\left(T_{\mathrm{em}}\right)$ :

$$
J_{g} \dot{\omega}_{g}=T_{\mathrm{hs}}-K_{g} \omega_{g}-T_{\mathrm{em}} .
$$

Gearbox ratio is defined as

$$
\begin{gathered}
n_{g}=\frac{T_{\mathrm{ls}}}{T_{\mathrm{hs}}}=\frac{\omega_{g}}{\omega_{\mathrm{ls}}}, \\
T_{\mathrm{ls}}=n_{g} T_{\mathrm{hs} .}
\end{gathered}
$$

From (10) the high speed shaft torque $T_{\mathrm{hs}}$ can be expressed as

$$
T_{\mathrm{hs}}=J_{g} \dot{\omega}_{g}+K_{g} \omega_{g}+T_{\mathrm{em}} .
$$

Putting the values of $T_{\mathrm{hs}}$ from (13) in (12) we get

$$
T_{\mathrm{ls}}=n_{g}\left(J_{g} \dot{\omega}_{g}+K_{g} \omega_{g}+T_{\mathrm{em}}\right) .
$$

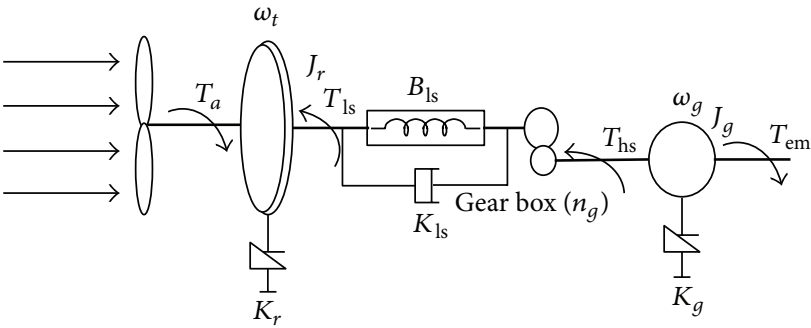

FIGURE 3: Two-mass model of the aero turbine.

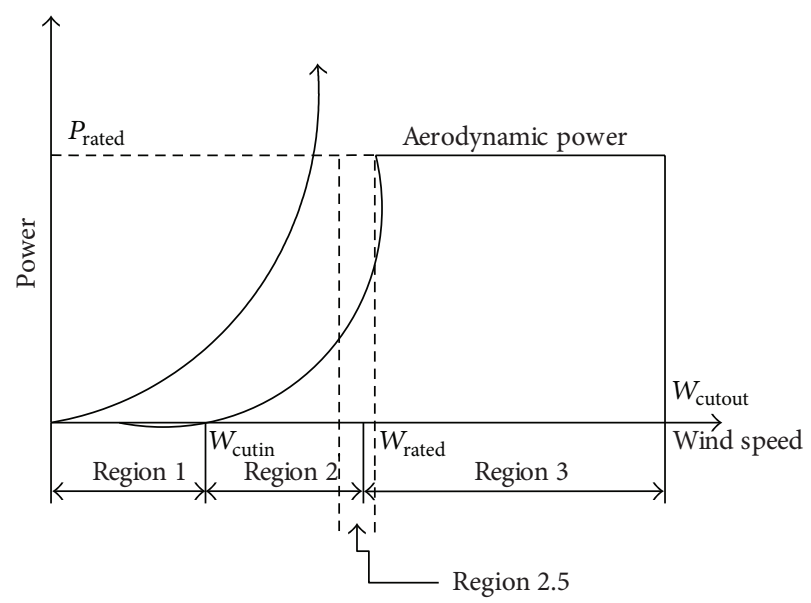

FIGURE 4: Power operating region of wind turbines.

\section{Problem Formulation}

Figure 4 shows the various operating region in VSVPWT.

Region 1 represents the wind speed below the cut in wind speed. Region 2 represents the wind speed between cut in and rated wind speed. In this region the main objective is to maximize the energy capture from the wind with reduced oscillation on the drive train. Region 2.5 represents the wind speed nearer to the rated wind speed, that is, transient period. Region 3 describes the wind speed above the rated wind speed. In this region pitch controller is used to maintain the $\mathrm{WT}$ at its rated power.

3.1. Control Structure. The time response of WT electrical system is much faster than the other parts of the WT. This makes it possible to decouple the generator and the aeroturbine control designs and thus define a cascaded control structure around two control loops.

(1) The inner control loop consists of electrical generator with power converters.

(2) The outer loop has the aeroturbine control which gives the reference to the inner loop.

Figure 5 shows the WT control levels. In this paper we made an assumption that the inner loop is well controlled. 


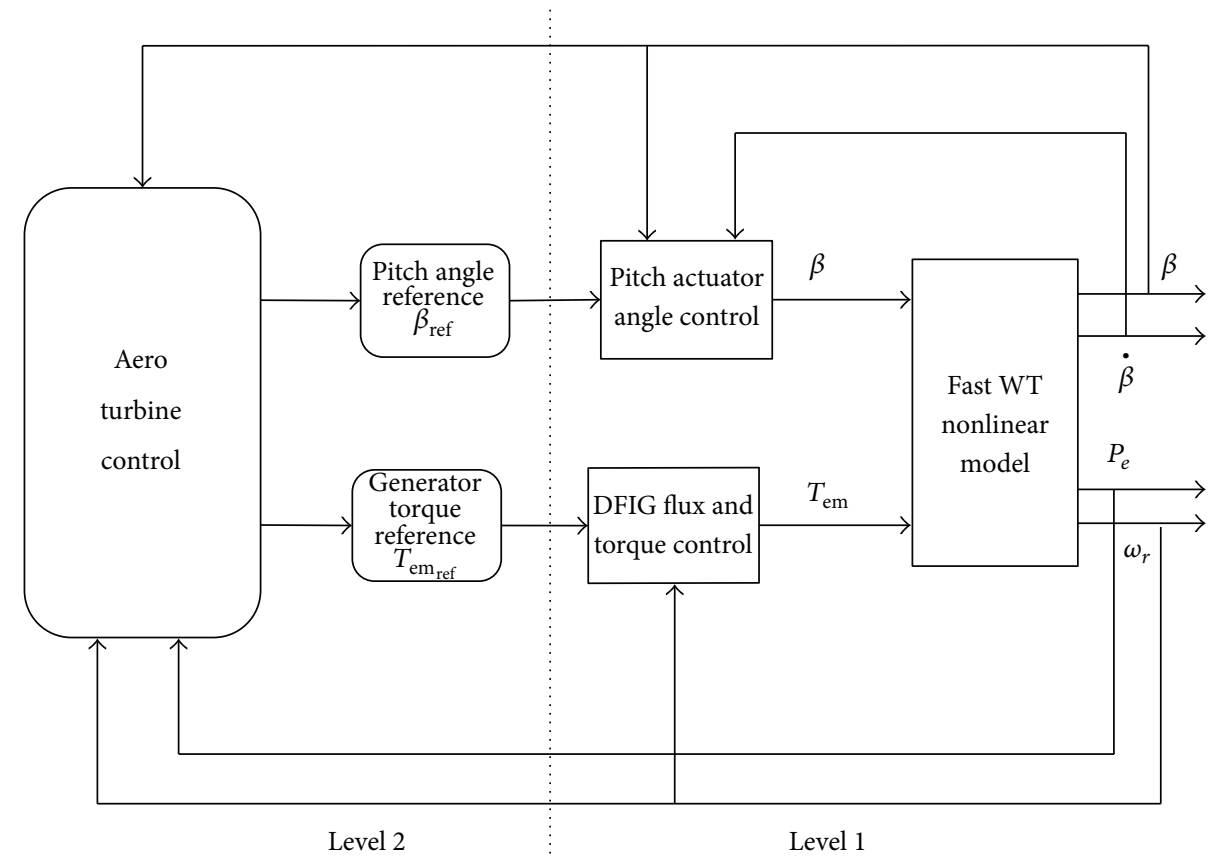

Figure 5: WT control levels.

3.2. Control Objective. In this work we consider two objectives. First objective is torque control for optimal power extraction with reduced oscillation on the drive train at below rated wind speed. To achieve the above objective (Region $2)$ the blade pitch angle $\left(\beta_{\text {opt }}\right)$ and tip speed ratio $\left(\lambda_{\text {opt }}\right)$ are set to be its optimal value. In order to achieve the optimal tip speed ratio the rotor speed must be adjusted to the reference/optimal rotor speed $\left(\omega_{r_{\text {opt }}}\right)$ by adjusting the control input that is, generator torque $\left(T_{g}\right)$. Equation (15) defines the reference/optimal rotor speed:

$$
\omega_{r_{\mathrm{opt}}}=\omega_{\mathrm{ref}}=\frac{\lambda_{\mathrm{opt}} v}{R} .
$$

Second objective is the pitch control for above rated wind speed, where torque control input is consider as maximum value. In region 3 only the pitch angle is varying according to the difference between the nominal speed and output generator speed. This work addresses both controller designs to achieve the control objectives for below and above wind speed.

3.3. Classical Control Techniques. In region 2 in order to compare the results of proposed and existing conventional controllers a brief description of the well-known control techniques, that is, ISC (indirect speed control) and ATF (aerodynamic torque feed-forward) are discussed in this section. In ISC, it is assumed that the WT is stable around its optimal aerodynamic efficiency curve. The two-mass model control signal is given in (16)

$$
T_{\mathrm{em}}=K_{\mathrm{opt}_{\mathrm{hs}}} \omega_{g}^{2}-K_{t_{\mathrm{hs}}} \omega_{g},
$$

where

$$
\begin{gathered}
K_{\mathrm{opt}_{\mathrm{hs}}}=0.5 \rho \pi \frac{R^{5}}{n_{g}^{3} \lambda_{\mathrm{opt}}^{3}} C_{P_{\mathrm{opt}},} \\
K_{t_{\mathrm{hs}}}=\left(K_{g}+\frac{K_{r}}{n_{g}^{2}}\right),
\end{gathered}
$$

where $K_{t_{\mathrm{hs}}}$ is the low speed shaft damping coefficient brought up to the high speed shaft.

In ATF, proportional control law is used to control the WT. The rotor speed and the aerodynamic torque $\left(T_{a}\right)$ are estimated using Kalman filter, which is used to control the WT [22]. The control law is given in (19)

$$
\begin{gathered}
T_{\mathrm{em}}=\frac{1}{n_{g}} \widehat{T}_{a}-\left(\frac{K_{r}}{n_{g}^{2}}+K_{g}\right) \widehat{\omega}_{g}-\frac{K_{\mathrm{C}}}{n_{g}^{2}}\left(\omega_{g_{\mathrm{ref}}}-\omega_{g}\right), \\
\omega_{g_{\mathrm{ref}}}=n_{g} k_{w} \sqrt{\widehat{T}_{a}}, \\
k_{w}=\frac{1}{\sqrt{k_{\mathrm{opt}}}}=\sqrt{\frac{2 \lambda_{\mathrm{opt}}^{3}}{\rho \pi R^{5} C_{P_{\mathrm{opt}}}}} \\
k_{\mathrm{opt}}=\frac{1}{2} \rho \pi \frac{R^{5}}{\lambda_{\mathrm{opt}}^{3}} C_{P_{\mathrm{opt}}}
\end{gathered}
$$

The optimal value of proportional gain is found to be $K_{c}=$ $3 \times 10^{4}$. The above existing control techniques have three major drawbacks, that is, the ATF control having more steady state error, so an accurate value of $\omega_{g_{\text {ref }}}$ is needed, and in 
ISC the WT has to operate at its optimal efficiency curve which introduces more power loss for high varying wind speed. Both the controllers are not robust with respect to disturbances. To avoid the above drawbacks two nonlinear controllers, that is, ISMC and SMC, are proposed in region 2. For region 3 control conventional proportional Integral (PI) control is considered.

3.4. Wind Speed Estimation. The estimation of effective wind speed is related to aerodynamic torque and rotor speed provided the pitch angle is at optimal value:

$$
T_{a}=\frac{1}{2} \rho \pi R^{3} \frac{C_{P}(\lambda)}{\lambda} v^{2}
$$

The aerodynamic power coefficient is approximated with 5 th order polynomial as given in (7):

$$
F(v)=T_{a}-\frac{1}{2} \rho \pi R^{3} \frac{C_{P}(\lambda)}{\lambda} v^{2} .
$$

The estimated wind speed can be obtained by solving (24) using MNR. The above equation has unique solution at below rated region. With known $v$ the optimal rotor speed $\omega_{r_{\text {opt }}}$ is calculated by using (15). The above wind speed estimation is only considered for below rated wind speed condition. Appendix B gives the steps for MNR algorithm.

\section{Control Techniques for Below and Above Rated Wind Speed}

4.1. Sliding Mode Control (SMC) for Optimal Power Extraction. The proposed control strategy combines MNR based estimator with second order sliding mode controller. SMC is one of the effective nonlinear robust approaches with respect to system dynamics and invariant to uncertainties. Lyapunov stability approach is used in SMC to keep the nonlinear system under control. The objective of the controller is to optimize the energy capture from the wind by tracking the reference rotor speed. In general designing SMC has two steps. First to find the sliding surface second is to develop the control signal $U$.

Time varying sliding surface is defined as

$$
S=\left(\lambda+\frac{d}{d t}\right)^{n-1} e(t)
$$

where $e(t)$ is defined as the difference between rotor speed and reference rotor speed, $n$ is the order of the system, and $\lambda$ is positive constant. Consider

$$
e(t)=\omega_{r}(t)-\omega_{\text {ref }}(t) .
$$

Finally the sliding surface is defined as

$$
S(t)=\lambda e(t)+\dot{e}(t) .
$$

Generally three types of reaching law are proposed [23]. Direct switching function method is applied in this work having the condition:

$$
S \dot{S} \leq 0
$$

The control should be chosen in such a way that the following candidate Lyapunov function satisfies Lyapunov stability criteria. Lyapunov candidate function is defined as

$$
V=\frac{1}{2} S^{2}
$$

A sufficient condition is that the system output should stay on the sliding surface, that is, $S(t)$. By taking the derivate of the Lyapunov function, $d V / d t \leq 0$ only when $S(t)=0$. From this it is clear that the defined control law is able to track the time varying reference signal, that is, rotor speed reference. If $V(0)=0$ then $d V / d t=0$, from this $d V / d t=S(d S / d t)$ so $d S / d t=0$

$$
\frac{d V}{d t}=S \frac{d S}{d t}=S(\lambda \dot{e}(t)+\ddot{e}(t))
$$

The convergence condition is given by the Lyapunov equation which makes the sliding surface attractive and invariant. At steady state the rotor should track the optimal rotor speed asymptotically; that is, $\omega_{r}(t) \rightarrow \omega_{\text {ref }}(t)$ as $t \rightarrow \infty$. Consider

$$
\begin{aligned}
\dot{V} & =S \dot{S}=S(\lambda \dot{e}(t)+\ddot{e}(t)) \\
& =S\left[\lambda\left(\dot{\omega}_{r}(t)-\dot{\omega}_{\text {ref }}(t)+\ddot{e}(t)\right)\right] .
\end{aligned}
$$

$\dot{V} \leq 0$ meets the following condition:

$$
\lambda\left(\dot{\omega}_{r}-\dot{\omega}_{\text {ref }}\right)+\ddot{e}(t) \begin{cases}<0 & \text { for } S>0 \\ =0 & \text { for } S=0 \\ >0 & \text { for } S<0 .\end{cases}
$$

The values of the control variable are to be set in such a way that the system will be stable. These control variables are given as follows:

$$
U \begin{cases}<T_{\mathrm{em}} & \text { for } S>0 \\ =T_{\mathrm{em}} & \text { for } S=0 \\ >T_{\mathrm{em}} & \text { for } S<0 .\end{cases}
$$

In order to derive the control input that is, $T_{\mathrm{em}}$, the following conversion has been made. By substituting the $\dot{\omega}_{r}(t)$ in (31) we get

$$
\lambda\left(\frac{1}{J_{r}} T_{a}-\frac{K_{r}}{J_{r}} \omega_{r}-\frac{1}{J_{r}} T_{\mathrm{ls}}-\dot{\omega}_{\mathrm{ref}}\right)+\ddot{e}(t)=0 .
$$

By using the relationship given in (14) finally we will get

$$
\begin{aligned}
& \lambda\left(\frac{T_{a}}{J_{r}}-\frac{K_{r}}{J_{r}} \omega_{r}-\frac{n_{g} J_{g} \dot{\omega}_{g}}{J_{r}}-\frac{n_{g} K_{g} \omega_{g}}{J_{r}}-\frac{n_{g}}{J_{r}} T_{\mathrm{em}}-\dot{\omega}_{\mathrm{ref}}\right) \\
& \quad+\ddot{e}(t)=0 .
\end{aligned}
$$

The control structure is defined as

$$
T_{\mathrm{em}}=\frac{T_{a}}{n_{g}}-\frac{K_{r}}{n_{g}}-J_{g} \dot{\omega}_{g}-K_{g} \omega_{g}-\frac{J_{r}}{n_{g}} \dot{\omega}_{\text {ref }}+\frac{J_{r}}{\lambda n_{g}} \ddot{e}(t) .
$$

Generally the SMC have two parts, that is, equivalent control $U_{\text {eq }}$ and switching control $U_{\text {sw }}$. The switching is used 
to avoid the parameter uncertainty and disturbances and the equivalent control is used to control the overall system behaviour, that is, tracking control:

$$
U(t)=U_{\text {eq }}(t)+U_{\text {sw }}(t) .
$$

The switching control is defined in two ways:

$$
U_{\text {sW }}(t)=k \operatorname{sign}(S) \quad \text { or } k \tanh \left(\frac{S}{\varphi}\right) .
$$

Generally the SMC with signum function introduces the chattering phenomenon in the system. This chattering introduces high frequency dynamics in the WT system, that is, control action to the system in undesirable. To neglect this chattering a smooth control discontinuity is introduced. As the signum function varies between -1 and +1 discontinuously, it is replaced by a tangent hyperbolic function (tanh). Finally the torque control structure is given in (39)

$$
\begin{aligned}
T_{\mathrm{em}}= & \frac{T_{a}}{n_{g}}-\frac{K_{r}}{n_{g}}-J_{g} \dot{\omega}_{g}-K_{g} \omega_{g}-\frac{J_{r}}{n_{g}} \dot{\omega}_{\text {ref }} \\
& +\frac{J_{r}}{\lambda n_{g}} \ddot{e}(t)+\frac{J_{r}}{n_{g} \lambda} k \tanh \left(\frac{S}{\varphi}\right),
\end{aligned}
$$

where " $k$ " is the sliding gain which is chosen based on the empirical results from the simulation. In summary the controller performance depends on the sliding gain and the boundary layer thickness. By using trial and error method the sliding gain is found to be 0.2 and boundary layer thickness is 1 for simulation. If the gain value increases more than 0.2 , it introduces more oscillation on the low speed shaft. The boundary layer is chosen arbitrarily that depends on the system performance.

\subsection{Integral Sliding Mode Control (ISMC) for Optimal Power} Extraction. To improve the sliding surface and overcome the steady state error the integral action is included in the sliding surface.

A sliding surface is defined as

$$
S(t)=\left(\lambda+\frac{d}{d t}\right)^{n-1} e(t)+K_{i} \int_{0}^{\infty} e(t) d t
$$

where $K_{i}$ is the integral gain.

The order of the system $n=2$ then the sliding surface modified as

$$
\begin{aligned}
S(t) & =\left(\lambda+\frac{d}{d t}\right)^{1} e(t)+K_{i} \int_{0}^{\infty} e(t) d t \\
& =\lambda e(t)+\dot{e}(t)+K_{i} \int_{0}^{\infty} e(t) d t .
\end{aligned}
$$

By taking the same Lyapunov function as mentioned in SMC with the same condition

$$
\begin{aligned}
\dot{V} & =S \dot{S}=S\left(\lambda \dot{e}(t)+\ddot{e}(t)+K_{i} e(t)\right) \\
& =S\left[\lambda\left(\dot{\omega}_{r}(t)-\dot{\omega}_{\mathrm{ref}}(t)+\ddot{e}(t)\right)+K_{i} e(t)\right] .
\end{aligned}
$$

$\dot{V} \leq 0$ meets the following condition:

$$
\lambda\left(\dot{\omega}_{r}-\dot{\omega}_{\text {ref }}\right)+\ddot{e}(t)+K_{i} e(t) \begin{cases}<0 & \text { for } S>0 \\ =0 & \text { for } S=0 \\ >0 & \text { for } S<0\end{cases}
$$

In order to derive the control input, that is, $T_{\mathrm{em}}$, the following conversion has been made. By substituting the $\dot{\omega}_{r}(t)$ in (41) we get

$$
\lambda\left(\frac{1}{J_{r}} T_{a}-\frac{K_{r}}{J_{r}} \omega_{r}-\frac{1}{J_{r}} T_{\mathrm{ls}}-\dot{\omega}_{\mathrm{ref}}\right)+\ddot{e}(t)+K_{i} e(t)=0 .
$$

Finally the torque control structure is given in

$$
\begin{aligned}
T_{\mathrm{em}}= & \frac{T_{a}}{n_{g}}-\frac{K_{r}}{n_{g}} \omega_{r}-J_{g} \dot{\omega}_{g}-K_{g} \omega_{g}-\frac{J_{r}}{n_{g}} \dot{\omega}_{\mathrm{ref}} \\
& +\frac{J_{r}}{n_{g} \lambda} \ddot{e}(t)+\frac{J_{r}}{n_{g} \lambda} K_{i} e(t)+\frac{J_{r}}{n_{g} \lambda} k \tanh \left(\frac{S}{\varphi}\right) .
\end{aligned}
$$

The necessary condition of ISMC is to eliminate the steady state error in conventional SMC. The linear sliding surface is

$$
S(t)=\dot{e}(t)+\lambda e(t) .
$$

By taking the Laplace transform of above equation

$$
S(S)=E(S)[S+\lambda] .
$$

The steady state error is calculated by applying the final value theorem (FVT) to conventional sliding surface:

$$
\lim _{t \rightarrow \infty} e(t)=\lim _{s \rightarrow 0} S E(S)=\lim _{s \rightarrow 0} \frac{S}{S+\lambda} \sum(S)=\frac{1}{\lambda k} \varphi .
$$

Equation (48) represents the conventional SMC having steady state error which is proportional to boundary layer thickness $(\varphi)$ and inversely proportional to the coefficient $\lambda$ and sliding gain $k$.

The steady state error is calculated by applying the final value theorem (FVT) to integral sliding surface:

$$
\dot{S}(t)=\lambda \dot{e}(t)+k_{i} e(t)+\ddot{e}(t) .
$$

By taking the Laplace transform of above equation

$$
\begin{gathered}
S * S(S)=E(S)\left[S^{2}+\lambda S+k_{i}\right] \\
\lim _{t \rightarrow \infty} e(t)=\lim _{s \rightarrow 0} S E(S)=\lim _{s \rightarrow 0} \frac{S}{S^{2}+\lambda S+k_{i}} \lim _{s \rightarrow 0} S \sum(S)=0 .
\end{gathered}
$$

4.3. Pitch Controller. For above rated wind speed the torque control output is fixed to its rated value that is, maximum value of the control input. In this condition a linear pitch control is introduced. The gain scheduled pitch control is allowed to maintain the generator speed around its nominal 
TABLE 2: CART 3 WT characteristics.

\begin{tabular}{lc}
\hline Rotor diameter & $43.3 \mathrm{~m}$ \\
Gear ratio & 43.165 \\
Tower height & $36.6 \mathrm{~m}$ \\
Nominal power & $600 \mathrm{kw}$ \\
Maximum generator torque & $3.753 \mathrm{kNm}$ \\
\hline
\end{tabular}

value [24]. To achieve the above objective, proportional + integral (PI) control is introduced:

$$
\begin{gathered}
\Delta \beta=K_{p} e(t)+K_{i} \int e(t) d t, \\
e(t)=\omega_{g_{\text {norm }}}-\omega_{g},
\end{gathered}
$$

where $\omega_{g_{\text {norm }}}$ is the nominal value of the generator speed, that is, $1600 \mathrm{rpm}$, and $\omega_{g}$ is the generator speed.

\section{Validation Results}

The numerical simulations are performed on the CART (controls advanced research turbine) WT model and the characteristics are given in Table 2. The CART is located at the NREL (National Renewable Energy Laboratory) National Wind center near Golden, Colorado. The CART3 is a threeblade variable speed, variable pitch WT with nominal power rating of $600 \mathrm{~kW}$. It has mainly three parts, that is, rotor, tower, and nacelle. The rotor includes blade and their attachment points are called hub which is maintained by the low speed shaft. The tower is a cantilever beam which supports a yaw bearing and nacelle. The yaw bearing allows the turbine to rotate in the wind speed direction. The nacelle houses the complete drive train assembly. It contains the gearbox, generator, and low speed shaft. The gearbox is directly connected to the squirrel cage induction generator through high speed shaft. The generator is connected to the grid through power electronics that can directly control generator torque [25]. The power electronics consists of three-phase PWM (pulse width modulation) converters with a constant dc link voltage. The main objective of the grid side converter is maintaining the $\mathrm{dc}$ link voltage constant $[26,27]$.

5.1. Description for Simulator. FAST is an aeroelastic WT simulator which is developed by NREL. It can able to model both two- and three-blade horizontal axis wind turbine (HAWT). This FAST code can predict both extreme and fatigue loads. The tower and flexible blade are modeled by using the assumed mode method. Other components are modeled as rigid bodies. An advanced certified code is used in FAST to model the aerodynamic behavior of the WT. WT loads are calculated by using BEM (blade element momentum) and multiple component of wind speed profile [28]. FAST code is approved by the Germanischer Lloyd (GL) Windenergie $\mathrm{GmbH}$ for calculating onshore WT loads for design and certification [29]. Due to the above advantages and exact nonlinear modeling of the WT, the proposed controllers are validated by using FAST. In general three blade

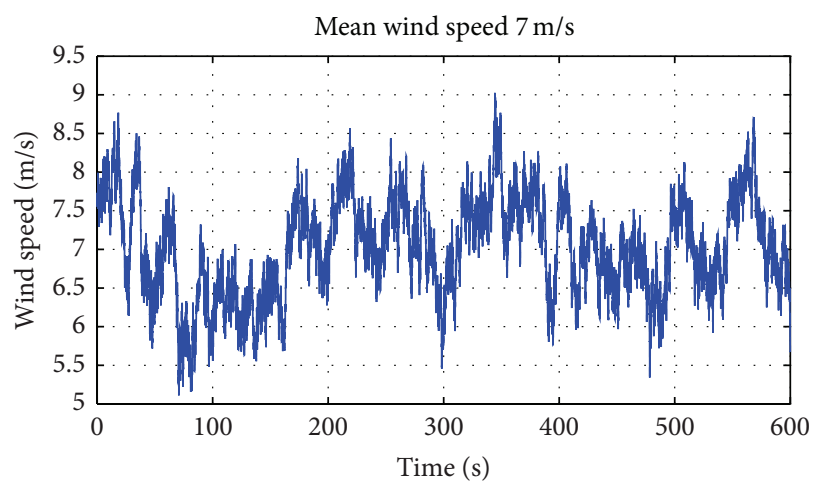

Figure 6: Test wind speed profile.

turbine has 24 DOF (degree of freedom) to represent the wind turbine dynamics. In this work $3 \mathrm{DOF}$ is considered for $\mathrm{WT}$, that is, variable generator, rotor speed, and blade teeter. FAST codes are interface with $S$-function and implemented with Simulink model. FAST uses an AeroDyn file as an input for aerodynamic part. AeroDyn file contains aerodynamic analysis routine and it requires status of a WT from the dynamic analysis routine and returns the aerodynamic loads for each blade element to the dynamic routine [30]. Wind profile acts as the input file for AeroDyn. The wind input file is generated by using TurbSim which is developed by the NREL.

In order to analysis the performance of the WT three cases are chosen.

5.2. Below Rated Wind Speed (Region 2). The test wind profile with full field turbulence is generated by using TurbSim developed by NREL. Figure 6 shows the hub height wind speed profile. In general any wind speed consists of two components, that is, mean wind speed and turbulence component. The test wind speed consists of $10 \mathrm{~min}$ dataset that was generated using Class A Kaimal turbulence spectra. It has the mean value of $7 \mathrm{~m} / \mathrm{s}$ at the hub height, turbulence intensity of $25 \%$, and normal IEC (International Electrotechnical Commission) turbulence type. The above wind speed is used as the excitation of WT.

The proposed and conventional controllers are implemented using FAST interface with MATLAB Simulink. Table 3 shows the comparisons of proposed and conventional controllers. The main objectives of the controllers are to maximize the energy capture with reduced stress on the drive train. The efficiency of the controllers is compared by using the following terms, that is, aerodynamic $\left(\eta_{\text {aero }}\right)$ and electrical $\left(\eta_{\text {elec }}\right)$ efficiency given in (53)

$$
\begin{aligned}
& \eta_{\text {aero }}(\%)=\frac{\int_{t_{\text {ini }}}^{t_{\text {fin }}} P_{a} d t}{\int_{t_{\text {ini }}}^{t_{\text {fin }}} P_{a_{\mathrm{opt}}} d t}, \\
& \eta_{\text {elec }}(\%)=\frac{\int_{t_{\text {ini }}}^{t_{\text {fin }}} P_{e} d t}{\int_{t_{\text {ini }}}^{t_{\text {fin }}} P_{a_{\text {opt }}} d t},
\end{aligned}
$$


TABLE 3: Comparison of different control strategy based on two-mass model using FAST simulator.

\begin{tabular}{lcccc}
\hline Control strategy & ISC & ATF & SMC & ISMC \\
\hline Std. $\left(T_{\text {ls }}\right)(\mathrm{kNm})$ & 9.629 & 23.03 & 21.84 & 13.59 \\
Max. $\left(T_{\text {ls }}\right)(\mathrm{kNm})$ & 45.62 & 130.8 & 131.4 & 73.4 \\
Std. $\left(T_{\mathrm{em}}\right)(\mathrm{kNm})$ & 0.142 & 0.369 & 0.252 & \\
Max. $\left(T_{\text {em }}\right)(\mathrm{kNm})$ & 1.010 & 2.500 & 1.690 & \\
$\eta_{\text {elec }}(\%)$ & 69.73 & 72.87 & 76.89 & \\
$\eta_{\text {aero }}(\%)$ & 85.59 & 85.06 & 96.78 & 76.260 \\
\hline
\end{tabular}

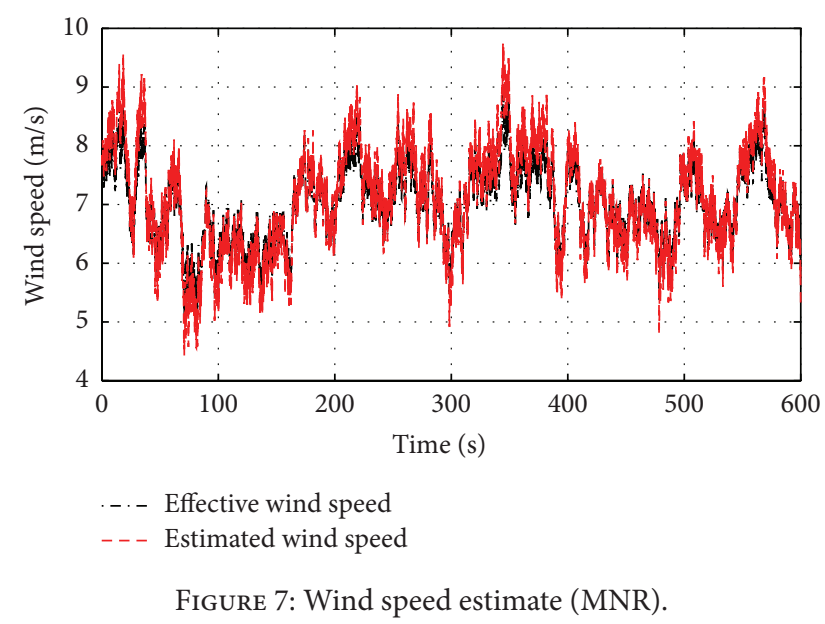

where $P_{a_{\text {opt }}}=0.5 \rho \pi R^{2} C_{P_{\text {opt }}}$ is the optimal aerodynamic power for the wind speed profile. The following objectives are used to measure the performance of the controllers.

(1) Maximization of the power capture is evaluated by the aerodynamic and electrical efficiency which is defined in (53).

(2) The reduced oscillation on the drive train and control torque smoothness are measured by the STD (Standard Deviation) and maximum value.

Figure 7 shows the estimation of effective wind speed by using the Modified Newton Raphson (MNR) estimator. The MNR estimator gives the correct reference which ensures the dynamic aspect of wind.

The rotor speed comparisons for FAST simulator are shown in Figures 8 and 9. The conventional controllers such as ATF and ISC are not able to track the optimal reference speed. ATF has only single tuning parameter, that is, $K_{c}$, which cannot minimize the steady state error. In ISC, during fast transient wind speed, it introduces more power loss. More over these controllers are not robust with respect to high turbulence wind speed profile. To overcome the above drawbacks SMC and ISMC are proposed. Figure 9 shows the rotor speed comparisons for ISMC and SMC. It is found that ISMC and SMC track the reference rotor speed better than ISC and ATF.

Table 3 gives the performance analysis of all the conventional and proposed controllers. From Table 3, it is clear that

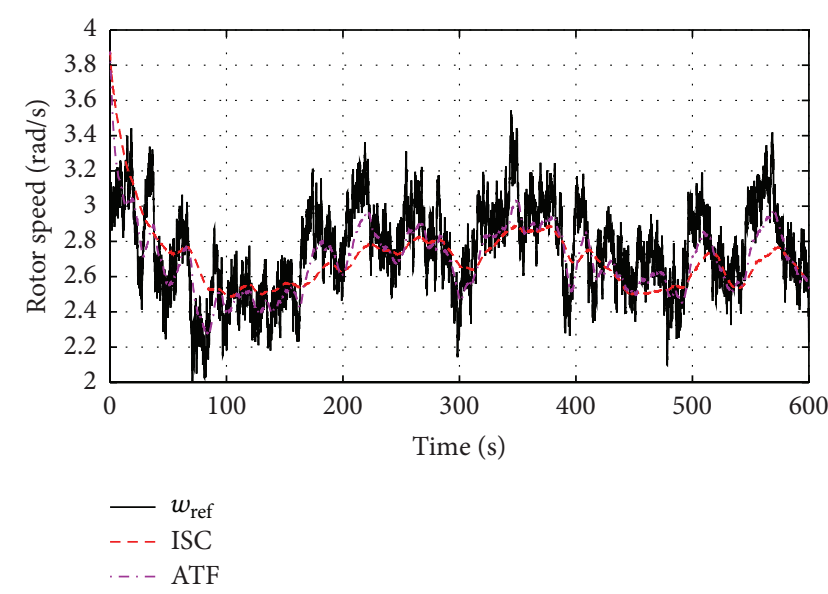

FIGURE 8: Rotor speed comparison for ATF and ISC for FAST simulator.

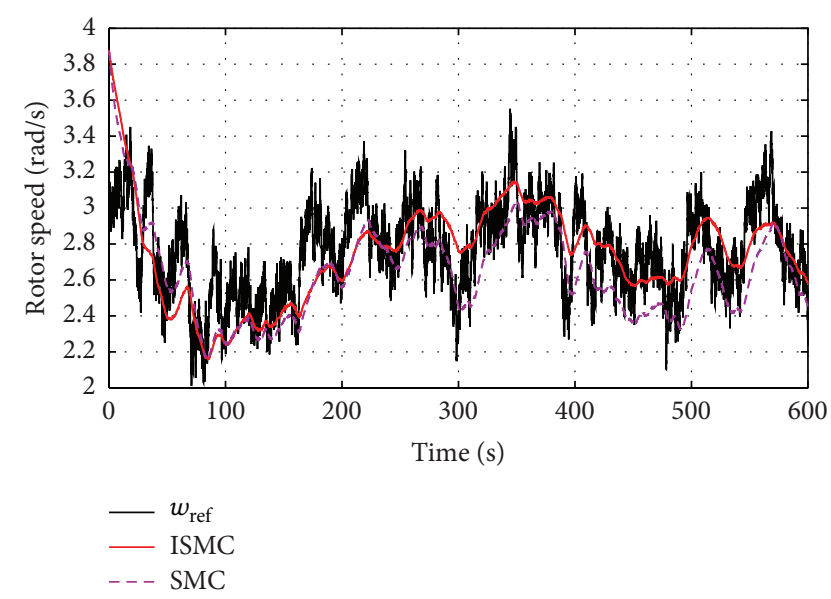

FIgURE 9: Rotor speed comparison for SMC and ISMC for FAST simulator.

the STD of $T_{\mathrm{em}}$ and $T_{\mathrm{ls}}$ is less for ISMC compared to SMC and ATF. This ensures the smoothness of the control input and low speed shaft torque in ISMC compared SMC and ATF. Table data shows that ISC having lowest STD of $T_{\mathrm{em}}$ and $T_{\mathrm{ls}}$, but its efficiency is very low (69.73\%) compared to all other controllers. So a trade-off should be made between the efficiency and the fatigue load on drive train. 


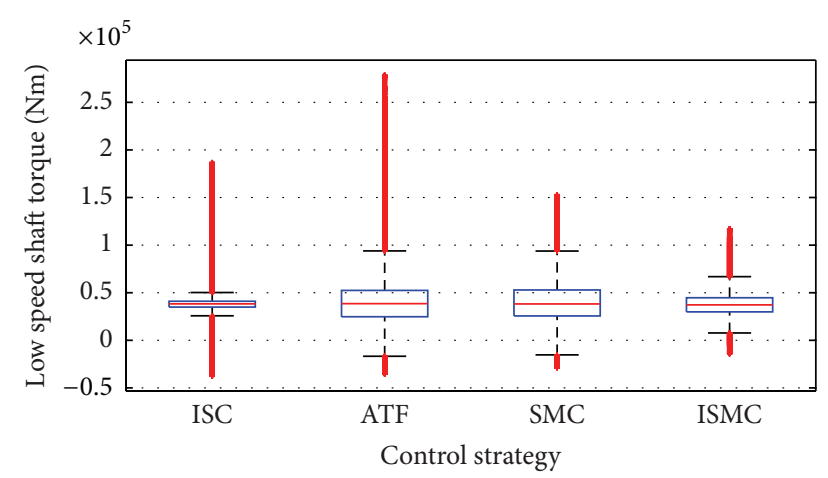

FIGURE 10: Boxplot for low speed shaft torque using FAST simulator.

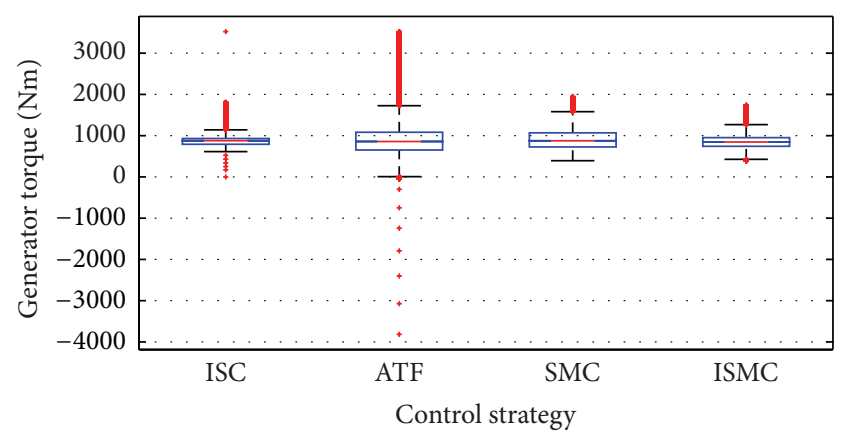

FIGURE 11: Boxplot for generator torque using FAST simulator.

To analyze the controller performances in a more detailed fashion, Figures 10 and 11 show the box plot for low speed shaft torque and generator torque with the mean, median, $\pm 25 \%$ quartiles (notch boundaries), $\pm 75 \%$ quartiles (box ends), $\pm 95 \%$ bounds, and the outliers. From the size of the boxes shown, it is clear that the ISC experiences minimum variation than others. It ensures that ISC having the minimum transient load on the drive train; at the same time, we have seen from Table 3 that the efficiency of ISC is not comparable with other controllers. Comparing the box plot of ISMC and SMC, ISMC has less variation in low speed shaft torque and generator torque; this indicates smoothness of the controller and reduction in transient load.

Figure 12 shows the boxplot for rotor speed for FAST simulator. From this figure it is observed that ISMC and SMC have almost same variation in the reference rotor speed. Apart from ISMC and SMC, other controllers such as ATF and ISC are having more variations in reference speed.

The frequency analysis is carried out by using the PSD on the low speed shaft torque which is shown in Figure 13. As the SMC plot is completely above the ISMC plot, it can be concluded that low speed shaft torque variation is more for SMC than ISMC. This indicates that ISMC gives minimum excitation to the drive train compared to SMC.

Figure 14 shows comparison of low speed shaft torque and control torque for ATF, SMC, and ISMC by considering ISC as baseline control. All the low speed shaft torques (LSSTq) and control torques (ControlTq) are having higher values compared to baseline controller.

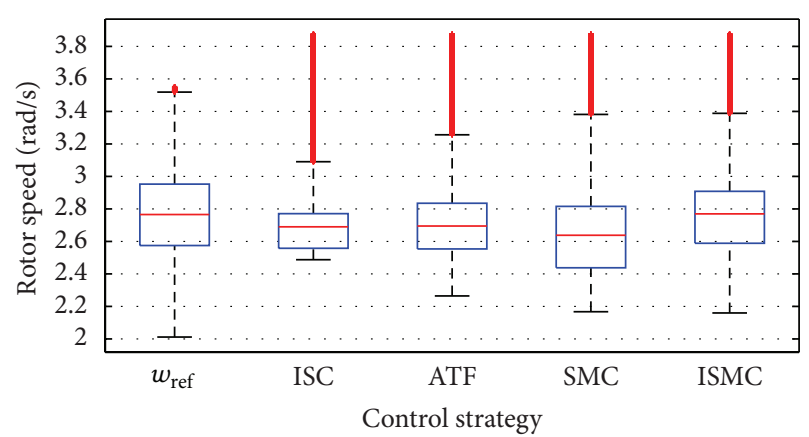

FIgURE 12: Boxplot for rotor speed using FAST Simulator.

TABLE 4: SMC performance for different wind speed profiles.

\begin{tabular}{lccc}
\hline $\begin{array}{l}\text { Mean wind } \\
\text { speed }(\mathrm{m} / \mathrm{sec})\end{array}$ & $\begin{array}{c}\text { Electrical } \\
\text { efficiency }(\%)\end{array}$ & $\begin{array}{c}T_{\mathrm{ls}} \text { standard } \\
\text { deviation } \mathrm{kNm}\end{array}$ & $\begin{array}{c}\mathrm{Max}\left(T_{\mathrm{em}}\right) \\
\mathrm{kNm}\end{array}$ \\
\hline $7(\mathrm{~m} / \mathrm{sec})$ & 76.89 & 21.84 & 1.690 \\
$8(\mathrm{~m} / \mathrm{sec})$ & 74.51 & 20.31 & 1.783 \\
$8.5(\mathrm{~m} / \mathrm{sec})$ & 74.22 & 20.11 & 1.922 \\
\hline
\end{tabular}

TABLE 5: ISMC performance for different wind speed profiles.

\begin{tabular}{lccc}
\hline $\begin{array}{l}\text { Mean wind } \\
\text { speed }(\mathrm{m} / \mathrm{sec})\end{array}$ & $\begin{array}{c}\text { Electrical } \\
\text { efficiency }(\%)\end{array}$ & $\begin{array}{c}T_{\mathrm{ls}} \text { standard } \\
\text { deviation } \mathrm{kNm}\end{array}$ & $\begin{array}{c}\mathrm{Max}\left(T_{\mathrm{em}}\right) \\
\mathrm{kNm}\end{array}$ \\
\hline $7(\mathrm{~m} / \mathrm{sec})$ & 76.26 & 13.59 & 1.260 \\
$8(\mathrm{~m} / \mathrm{sec})$ & 74.49 & 11.72 & 1.526 \\
$8.5(\mathrm{~m} / \mathrm{sec})$ & 74.68 & 11.98 & 1.762 \\
\hline
\end{tabular}

As shown in Figure 15 the SMC controller has improved power capture by $0.75 \%$ compared to ISMC. An intermediate tracking has been chosen and a compromise has been made between efficiency and load mitigation. From the above analysis and results given in Table 3 it is observed that even though SMC gives slightly more efficiency than ISMC, by considering transient load on drive train and smooth control input, ISMC found be optimal.

In order to avoid the torsional resonance mode by choosing the proper tracking dynamics a trade-off is made between power capture optimization with smooth control and reduced transient load on low speed shaft torque. A good dynamic tracking; that is, similar to WT fast dynamics gives better power capture but it requires more turbulence in control torque. Conversely slow tracking gives smooth control action with less power capture. The simulations are performed with different mean wind speed at region 2 . The results are given in Tables 4 and 5. From these tables it observed that with an increase in mean wind speed the maximum value of the control input $\left(T_{\mathrm{em}}\right)$ also increases. In all the cases both SMC and ISMC controllers are having almost same efficiency but the transient load reduction is better for ISMC. As the mean wind speed increases the rate of increase of STD is more for SMC than ISMC. It observed that when the wind speed undergoes high variation the ISMC can produce better power capture with reduced transient load on the drive train. 


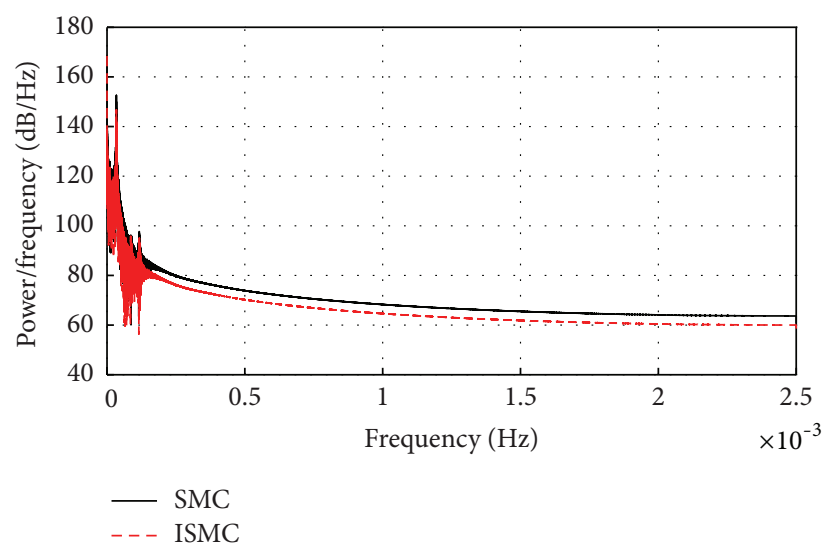

FIGURE 13: PSD for low speed shaft torque using FAST simulator.

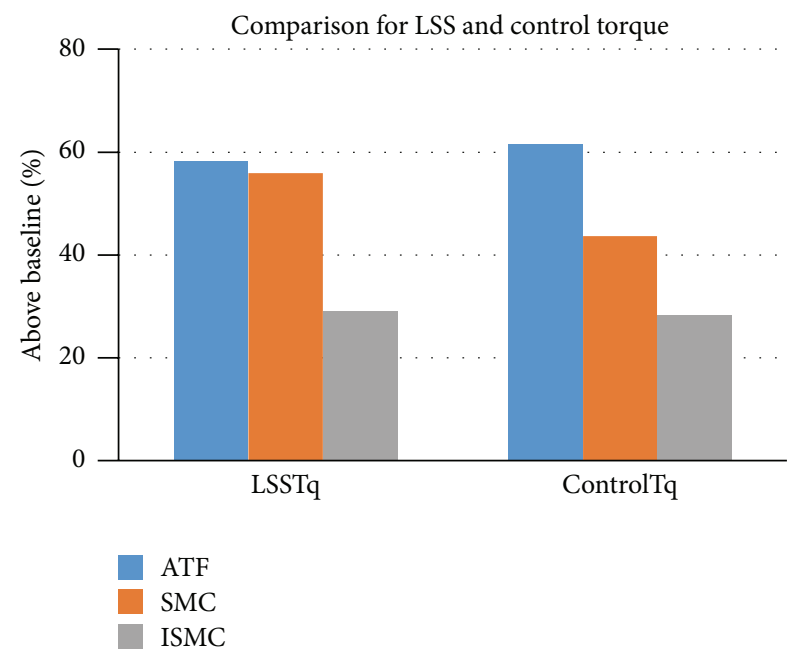

FIGURE 14: Comparison for baseline control with other controllers for LSS and control torque.

5.3. Transition between Below and Above Rated Wind Speed (Region 2.5). Figure 16(a) shows the test wind speed consists of $10 \mathrm{~min}$ dataset that was generated by the binary file format. In this wind profile the wind speed changes in step of every $50 \mathrm{sec}$ starts from $6 \mathrm{~m} / \mathrm{sec}$ to $18 \mathrm{~m} / \mathrm{sec}$. This shows both the above and below rated wind speed are included in the wind profile. For below rated wind speed torque control comes into action with constant pitch angle and above rated wind speed pitch control comes into action with rated torque. Figure 16(b) shows the generator speed for SMC and ISMC for below and above rated wind speed. Both controllers achieve the nominal value of the generator speed at $250 \mathrm{sec}$. The corresponding wind speed is around $11.5 \mathrm{~m} / \mathrm{sec}$ which can be seen from Figure 16(a). As the wind speed approaches towards the rated speed the WT generator speed reaches the nominal value, that is, $167.55 \mathrm{rad} / \mathrm{sec}$. Figure 16(c) shows the electrical power comparison for SMC and ISMC for

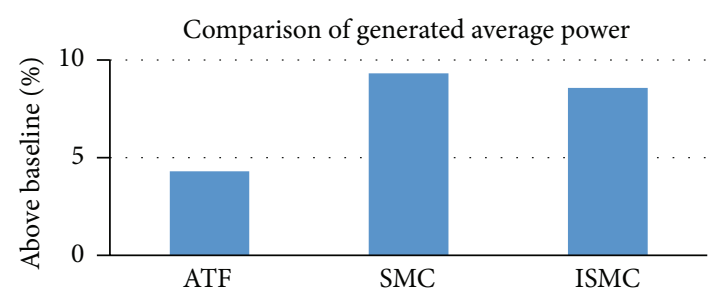

FIGURE 15: Comparison for baseline control with other controllers for generated average power.

the transition period. At region 2.5 ISMC can able to extract the more power than SMC with almost same mechanical stress on the drive train. Figure 16(d) shows the generator torque comparison in region 2.5 for SMC and ISMC. It can be observed that ISMC produces more generated torque compared to SMC in region 2.5, that is, $250 \mathrm{sec}$ to $400 \mathrm{sec}$. As generator speed remains constant from $200 \mathrm{sec}$ onwards it is obvious that ISMC captures more power compared to SMC. The STD of generated torque for SMC and ISMC is found to be $1.060 \mathrm{kNm}$ and $1.07 \mathrm{kNm}$ respectively which is almost same. Figure 16(e) shows the pitch angle comparison for SMC and ISMC at region 2.5. Pitch variation found to be more for SMC compared to ISMC. So the pitch actuator needs more control action for SMC + PI.

Figure 17(a) shows the test wind speed consists of $10 \mathrm{~min}$ dataset that was generated by the binary file format. In this wind profile the wind speed changes with vertical wind profile starts from $6 \mathrm{~m} / \mathrm{sec}$ to $18 \mathrm{~m} / \mathrm{sec}$. This shows both the above and below rated wind speed are included in the wind profile. Figure 17(b) shows the generator speed for SMC and ISMC for below and above rated wind speed. Both controllers achieve the nominal value of the generator speed at $280 \mathrm{sec}$. The corresponding wind speed is around $11.5 \mathrm{~m} / \mathrm{sec}$ which can be seen from Figure 17(a). As the wind speed approaches towards the rated speed the WT generator speed reaches the nominal value, that is, $167.55 \mathrm{rad} / \mathrm{sec}$. Figure $17(\mathrm{c})$ shows the electrical power comparison for SMC and ISMC for the transition period. At region 2.5 ISMC can extract more power than SMC with almost the same mechanical stress on the drive train. Figure 17(d) shows the generator torque comparison in region 2.5 for SMC and ISMC. It can be observed that ISMC produces more generated torque compared to SMC in region 2.5, that is, $280 \mathrm{sec}$ to $415 \mathrm{sec}$. As generator speed remains constant from $280 \mathrm{sec}$ onwards it is obvious that ISMC captures more power compared to SMC. Figure 16(e) shows the pitch angle comparison for SMC and ISMC at region 2.5. Pitch variation was found to be more for SMC compared to ISMC. So the pitch actuator needs more control action for SMC + PI.

Figure 18 shows the rotor speed comparison of SMC and ISMC controller with the rotor inertia parameter uncertainty $(+30 \%)$ and disturbance of $5 / n_{g} \mathrm{kNm}$. From this figure it is concluded that with the disturbance and uncertainty ISMC can track the reference rotor speed which ensures the robustness with respect to uncertainty and disturbance. 

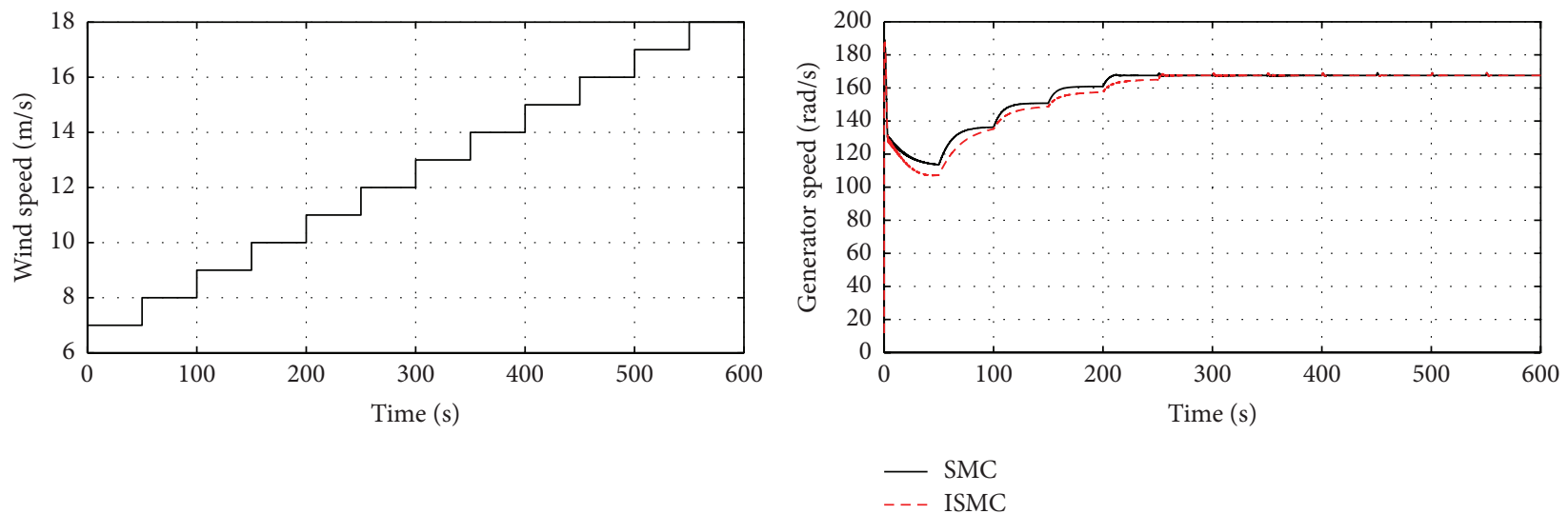

(a)

(b)
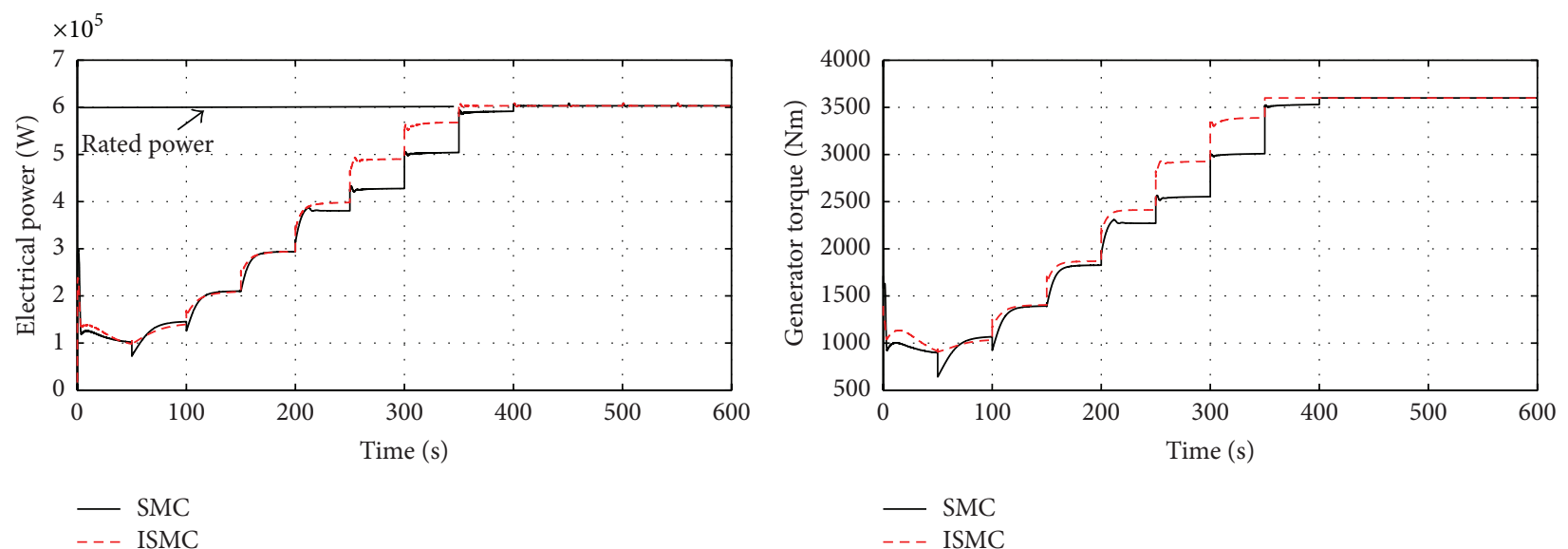

(c)

(d)

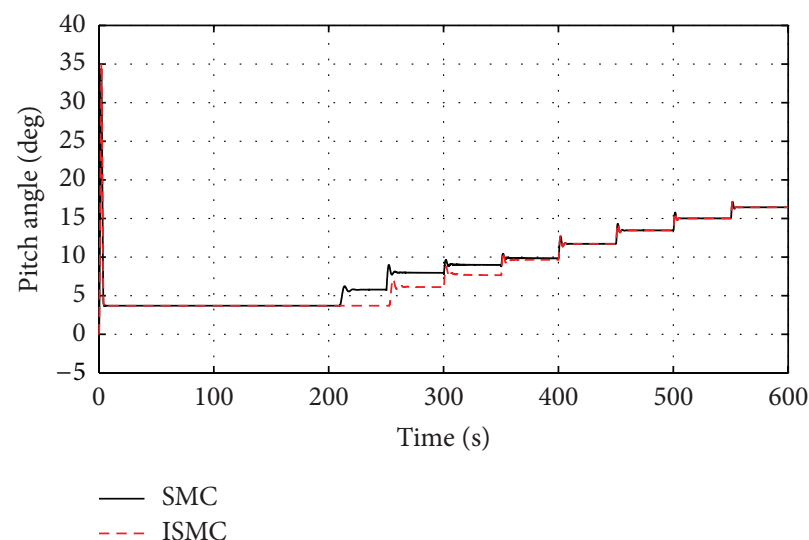

(e)

FIGURE 16: Simulation results of $600 \mathrm{~kW}$ CART 3 WT using SMC and ISMC in full range of operation (step change wind profile). (a) Wind speed profile, (b) generator speed, (c) electrical power, (d) generator torque, and (e) pitch angle. 


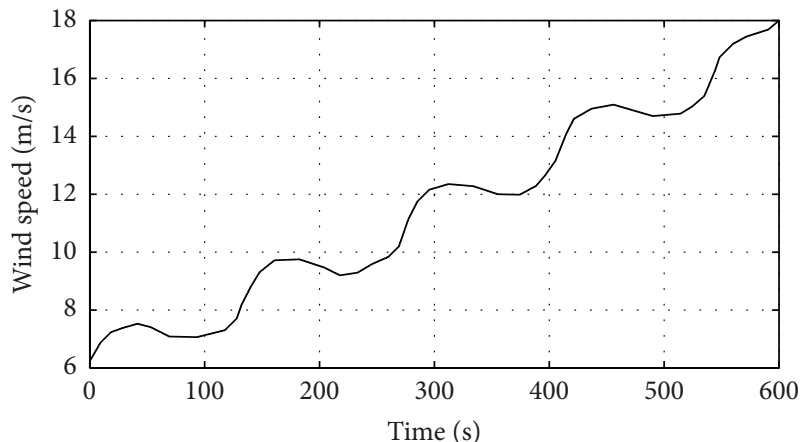

(a)

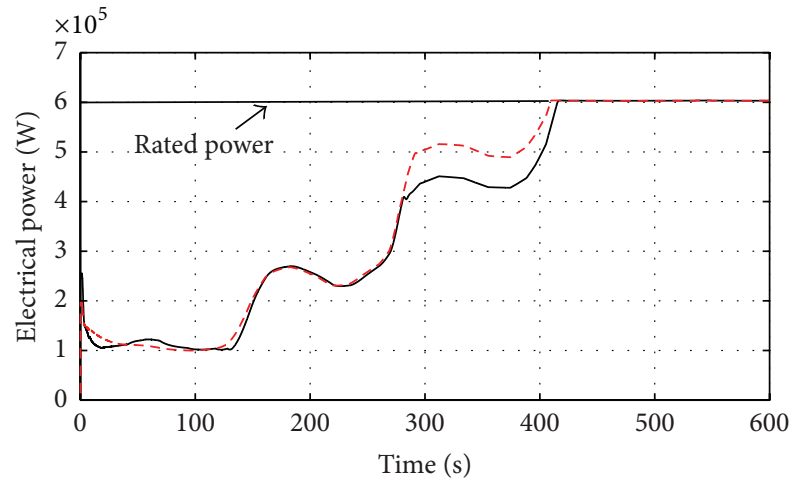

- SMC

-.. ISMC

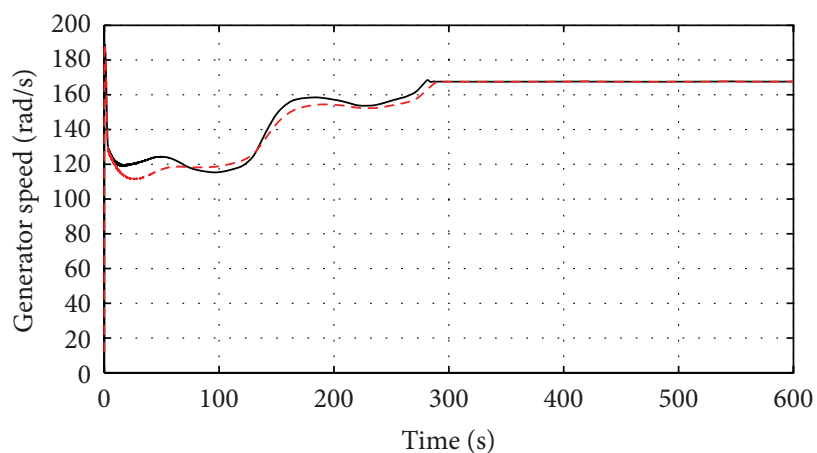

- SMC

-. - ISMC

(b)

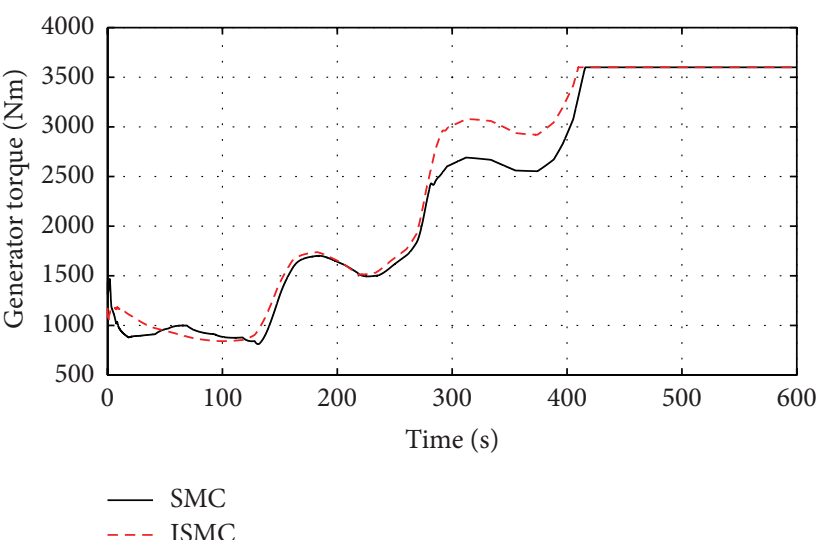

(d)

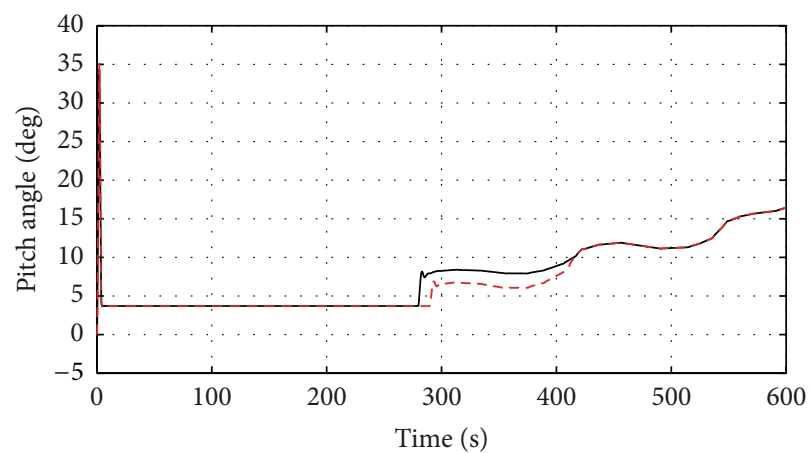

- SMC

-.. ISMC

(e)

FIGURE 17: Simulation results of $600 \mathrm{~kW}$ CART $3 \mathrm{WT}$ using SMC and ISMC in full range of operation (vertical wind profile). (a) Wind speed profile (b) generator speed, (c) electrical power, (d) generator torque, and (e) pitch angle.

\section{Conclusion}

In this paper a combination of linear and nonlinear control for VSVPWT has been proposed. The proposed nonlinear controller such as SMC and ISMC is designed for wide range of below rated wind speed profiles. The main aim of the controller is to capture the maximum power with reduced oscillation on the drive train at below rated speed. The simulation of the controllers is performed by NREL CART $3,600 \mathrm{~kW}$ WT. From the analysis it is concluded that the 


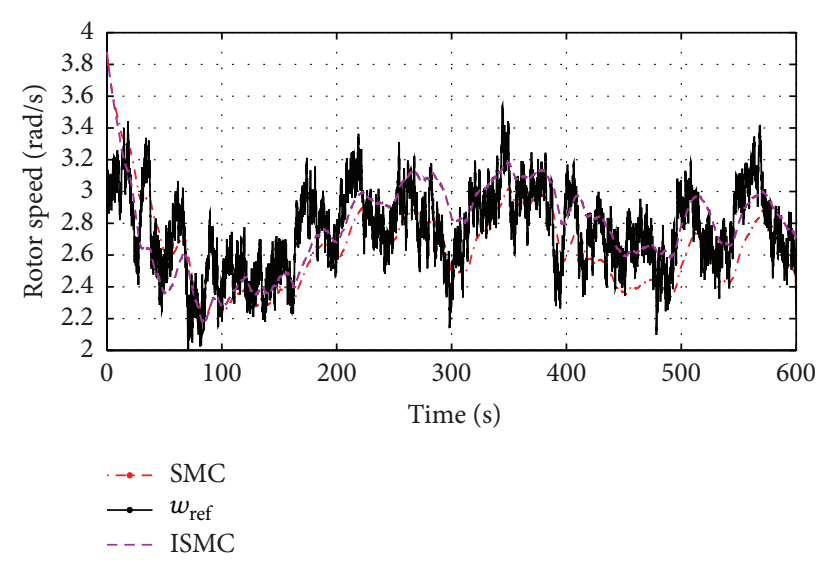

FIGURE 18: Rotor speed comparison of controllers with parameter uncertainty and disturbance of $5 / n_{g} \mathrm{kNm}$.

proposed ISMC (region 2) with conventional PI controller (region 3) can achieve the maximum power in all the regions of wind speed.

\section{Appendices}

\section{A. Two-Mass Model Parameters}

Rotor radius: $R=21.65 \mathrm{~m}$,

air density: $\rho=1.29 \mathrm{~kg} / \mathrm{m}^{3}$,

rotor inertia: $J_{r}=3.25 \cdot 10^{5} \mathrm{~kg} \cdot \mathrm{m}^{2}$,

generator inertia: $J_{g}=34.4 \mathrm{~kg} \cdot \mathrm{m}^{2}$,

shaft damping coefficient: $K_{\mathrm{ls}}=9500 \mathrm{Nm} / \mathrm{rad}$,

shaft stiffness coefficient: $B_{\mathrm{ls}}=2.691 \cdot 10^{5} \mathrm{Nm} / \mathrm{rad}$,

rotor friction coefficient: $K_{r}=27.36 \mathrm{Nm} / \mathrm{rad} / \mathrm{sec}$,

generator friction coefficient: $K_{g}=0.2 \mathrm{Nm} / \mathrm{rad} / \mathrm{sec}$,

gear ratio: $n_{g}=43.165$,

cut in wind speed: $6 \mathrm{~m} / \mathrm{sec}$,

rated wind speed: $13 \mathrm{~m} / \mathrm{sec}$,

cut out wind speed: $25 \mathrm{~m} / \mathrm{sec}$.

\section{B. Modified Newton Raphson Algorithm}

The estimation of effective wind speed is done by using the modified Newton Raphson. At instant $t$ the effective wind speed is obtained from rotor speed and aerodynamic torque:

Step 1: $v_{0}=\widehat{v}\left(t-T_{s}\right)$,

Step 2: $v_{n+1}=\bar{v}_{n}-F(v) \cdot F^{\prime}(v) /\left(\left(F^{\prime}(v)\right)^{2}-(F(v) \bullet\right.$ $\left.F^{\prime \prime}(v)\right)$ ),

Step 3: $n=n+1$,

Step 4: Stop if $n>n_{\max }$ or $\left|v_{n}-v(n-1)\right| / v_{n}<\varepsilon_{\min }$ go to Step 2,

Step 5: $n_{f}=n$,

where $v_{n}$ is the result of the first $n$ iterations and $T_{s}$ is the sampled rate fixed here as $1 \mathrm{sec}$.

\section{Conflict of Interests}

The authors declare that there is no conflict of interests regarding the publication of this paper.

\section{References}

[1] T. Burton, D. Sharpe, N. Jenkins, and E. Bossanyi, Wind Energy Handbook, Wiley Publications, New York, NY, USA, 2001.

[2] F. D. Bianchi, F. D. Battista, and R. J. Mantz, Wind Turbine Control Systems: Principles, Modelling and Gain Scheduling Design, Springer, 2nd edition, 2006.

[3] Y. Lei, A. Mullane, G. Lightbody, and R. Yacamini, "Modeling of the wind turbine with a doubly fed induction generator for grid integration studies," IEEE Transactions on Energy Conversion, vol. 21, no. 1, pp. 257-264, 2006.

[4] Y. D. Song, B. Dhinakaran, and X. Y. Bao, "Variable speed control of wind turbines using nonlinear and adaptive algorithms," Journal of Wind Engineering and Industrial Aerodynamics, vol. 85, no. 3, pp. 293-308, 2000.

[5] M. Liao, L. Dong, L. Jin, and S. Wang, "Study on rotational speed feedback torque control for wind turbine generator system," in Proceedings of the International Conference on Energy and Environment Technology (ICEET '09), pp. 853-856, October 2009.

[6] M. Sheikhan, R. Shahnazi, and A. Nooshad Yousefi, "An optimal fuzzy PI controller to capture the maximum power for variablespeed wind turbines," Neural Computing and Applications, vol. 23, no. 5, pp. 1359-1368, 2013.

[7] K. Z. Østergaard, P. Brath, and J. Stoustrup, "Estimation of effective wind speed," Journal of Physics: Conference Series, vol. 75, no. 1, Article ID 012082, 2007.

[8] B. Boukhezzar, H. Siguerdidjane, and M. Hand, "Nonlinear control of variable-speed wind turbines for generator torque limiting and power optimization," Transactions of the ASME, Journal of Solar Energy Engineering, vol. 128, no. 4, pp. 516-530, 2006.

[9] B. Boukhezzar and H. Siguerdidjane, "Nonlinear control of a variable-speed wind turbine using a two-mass model," IEEE Transactions on Energy Conversion, vol. 26, no. 1, pp. 149-162, 2011.

[10] B. Beltran, T. Ahmed-Ali, and M. E. H. Benbouzid, "High-order sliding-mode control of variable-speed wind turbines," IEEE Transactions on Industrial Electronics, vol. 56, no. 9, pp. 33143321, 2009.

[11] A. Khamlichi, B. Ayyat, R. O. B. Zarouala, and C. V. Venegas, "Advanced control based on extended kalman filter for variable speed wind turbine," Australian Journal of Basic and Applied Sciences, vol. 5, no. 9, pp. 636-644, 2011.

[12] I. Ćirić, Ž. Ćojbašić, V. Nikolić, and E. Petrović, "Hybrid fuzzy control strategies for variable speed wind turbines," Facta Universitatis, Series: Automatic Control and Robotics, vol. 10, no. 2, pp. 205-217, 2011.

[13] R. Rocha, "A sensorless control for a variable speed wind turbine operating at partial load," Renewable Energy, vol. 36, no. 1, pp. 132-141, 2011

[14] Z. Xu, Q. Hu, and M. Ehsani, "Estimation of effective wind speed for fixed-speed wind turbines based on frequency domain data fusion," IEEE Transactions on Sustainable Energy, vol. 3, no. 2, pp. 57-64, 2012. 
[15] B. Boukhezzar, L. Lupu, H. Siguerdidjane, and M. Hand, "Multivariable control strategy for variable speed, variable pitch wind turbines," Renewable Energy, vol. 32, no. 8, pp. 1273-1287, 2007.

[16] J. O. M. Rubio and L. T. Aguilar, "Maximizing the performance of variable speed wind turbine with nonlinear output feedback control," Procedia Engineering, vol. 35, pp. 31-40, 2012.

[17] M. A. Ayoubi and L.-C. Tai, "Intelligent control of a large Variable speed Wind turbine," Journal of Solar Energy Engineering, vol. 134, no. 1, Article ID 011001, 2012.

[18] H. Jafarnejadsani, J. Pieper, and J. Ehlers, "Adaptive control of a variable-speed variable-pitch wind turbine using radial-basis function neural network," IEEE Transactions on Control Systems Technology, vol. 21, no. 6, pp. 2264-2272, 2013.

[19] W. Zhang and H. Xu, "Active disturbance rejection based pitch control of variable speed wind turbine," in Proceedings of the 30th Chinese Control Conference, pp. 5094-5098, July 2011.

[20] A. Abdullah and A. Fekih, "Pitch control design for optimum energy capture in variable-speed wind turbines," in Proceedings of the 10th International Multi-Conference on Systems, Signals and Devices (SSD '13), pp. 1-6, Hammamet, Tunisia, March 2013.

[21] A. S. Yilmaz and Z. Özer, "Pitch angle control in wind turbines above the rated wind speed by multi-layer perceptron and radial basis function neural networks," Expert Systems with Applications, vol. 36, no. 6, pp. 9767-9775, 2009.

[22] H. Vihriälä, R. Perälä, P. Mäkilä, and L. Söderlund, "A gearless wind power drive: part 2: performance of control system," in Proceedings of the European Wind Energy Conference, vol. 1, pp. 1090-1093, 2001.

[23] P. Ben-Tzvi, S. Bai, Q. Zhou, and X. Huang, "Fuzzy sliding mode control of rigid-flexible multibody systems with bounded inputs," Transactions of the ASME, Journal of Dynamic Systems, Measurement and Control, vol. 133, no. 6, Article ID 061012, pp. $1-8,2011$.

[24] M. H. Hansen, A. Hansen, T. J. Larsen, S. Øye, P. Sørensen, and P. Fuglsang, Control Design for a Pitch Regulated Variable Speed Wind Turbine, Riso National Laboratory, 2005.

[25] L. J. Fingersh and K. Johnson, "Controls advanced research turbine (CART) commissioning and baseline data collection," NREL Report TP-500-32879, National Renewable Energy Laboratory, Golden, Colo, USA, 2002.

[26] R. Ottersten, On control of back-to-back converters and sensorless induction machine drives [Ph.D. thesis], Chalmers University of Technology, Göteborg, Sweden, 2003.

[27] R. Peña, R. Cardenas, R. Blasco, G. Asher, and J. Clare, "A cage induction generator using back to back PWM converters for variable speed grid connected wind energy system," in Proceedings of the 27th Annual Conference of the IEEE Industrial Electronics Society (IECON '01), pp. 1376-1381, December 2001.

[28] M. Hansen, J. Sørensen, S. Voutsinas, N. Sørensen, and H. Madsen, "State of the art in wind turbine aerodynamics and aeroelasticity," Progress in Aerospace Sciences, vol. 42, no. 4, pp. 285-330, 2006.

[29] A. Manjock, "Design codes FAST and ADAMS for load calculations of onshore wind turbines," Tech. Rep. 72042, Germanischer Lloyd, Windenergie GmbH, Hamburg, Germany, 2005.

[30] D. J. Laino and A. C. Hansen, User's Guide to the Wind Turbine Aerodynamics Computer Software Aerodyn, National Wind Technology Center, National Renewable Energy Laboratory, Golden, Colo, USA, 12.50 edition, 2003. 


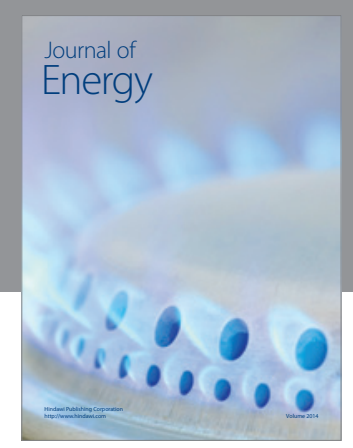

Journal of

Industrial Engineering
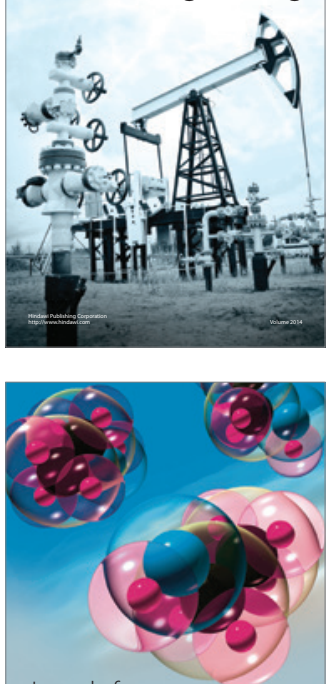

Fuels
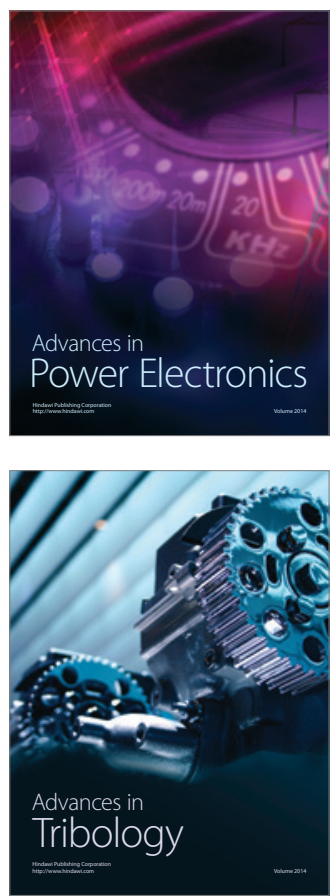

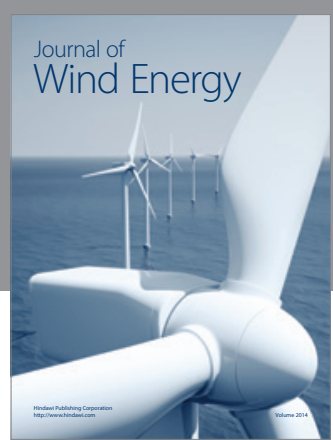

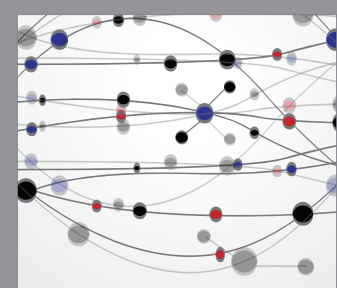

The Scientific World Journal

Submit your manuscripts at http://www.hindawi.com

Journal of

Structures
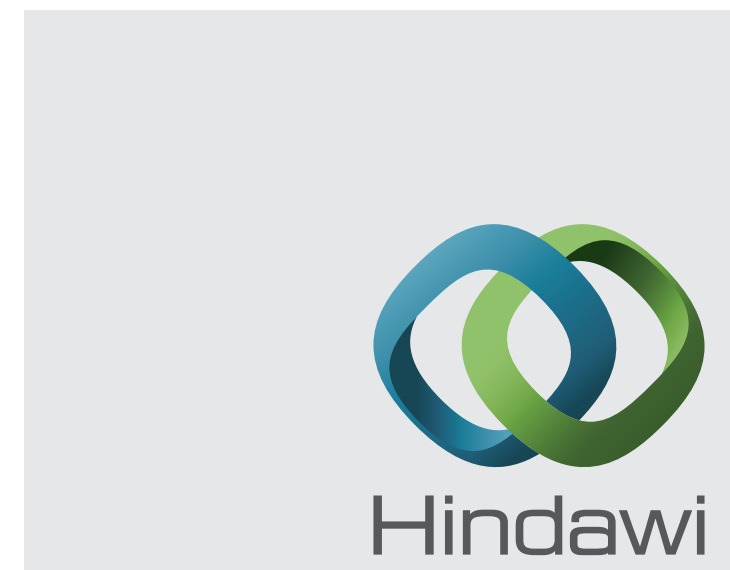

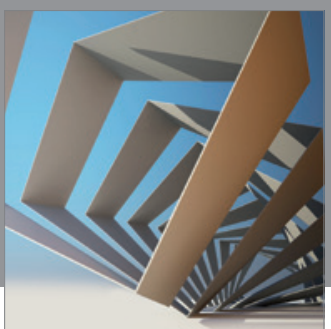

Rotating

Machinery
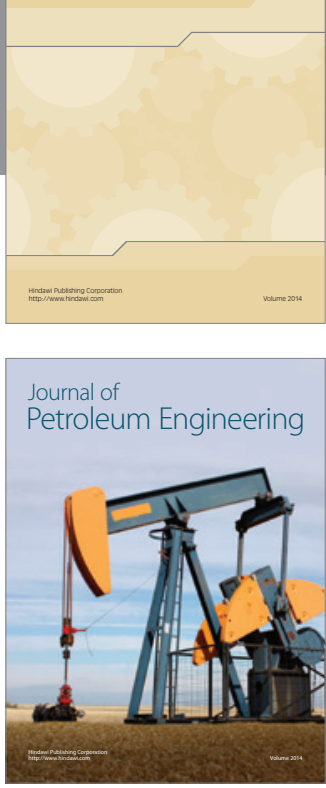

Journal of

Solar Energy
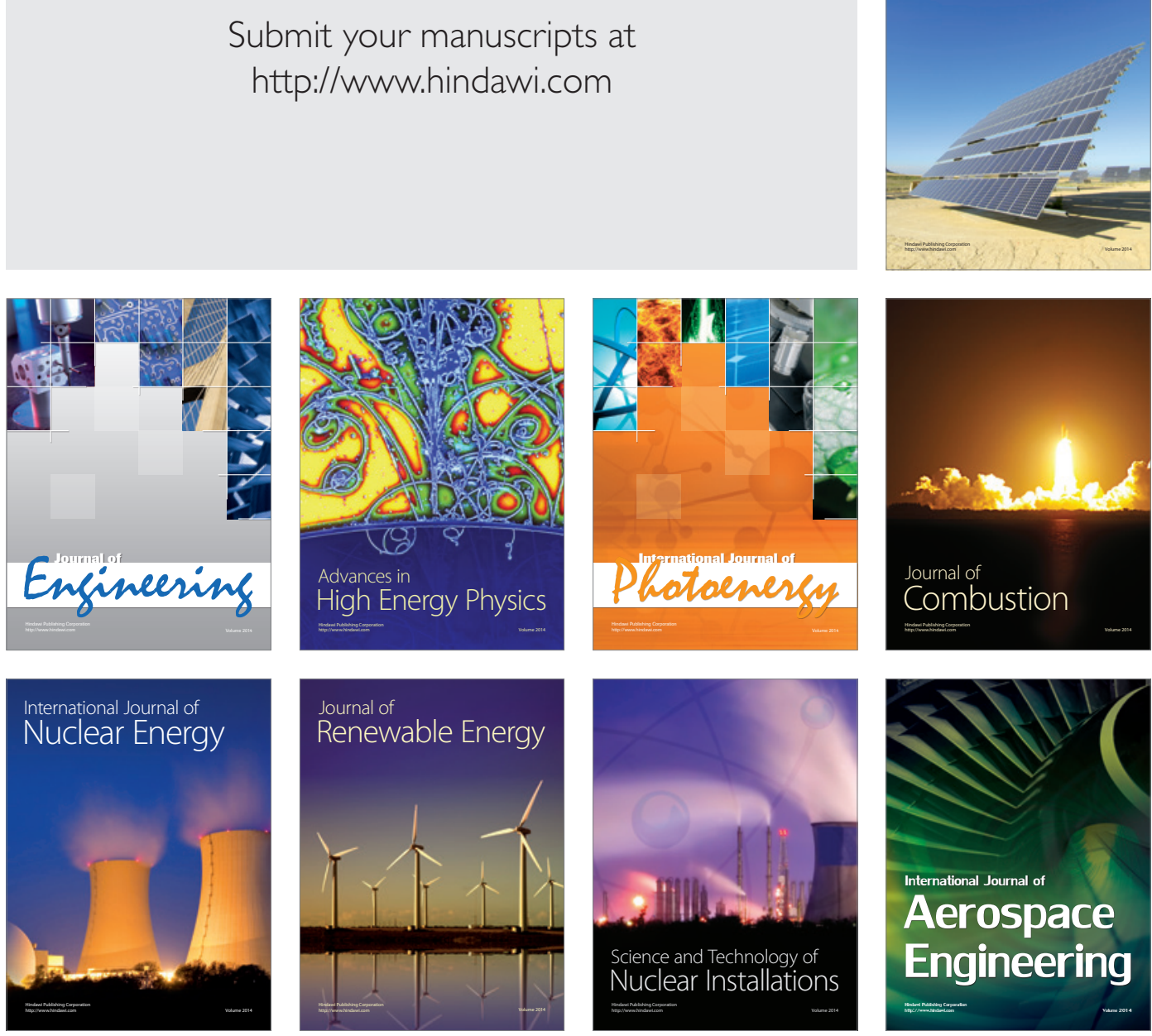